\title{
Astronomical Education in Poland
}

\section{Katarzyna Turaj}

Institute of Physics, Wyzsza Szkola Pedagogiozna, ul. Podchorazyc nr. 2, PL-30084 Krakow, Poland

Astronomical education is undergoing a fundamental change in Poland with the introduction in 1987 September of a revised astronomy programme. Although previously taught as a separate subject, it was often neglected by pupils concentrating on examinations for other subjects. Astronomy is now treated as part of the physics course and will be taught to all grades of pupils. This contribution also described the encouragement of astronomy through school astronomy groups, summer camps and the Astronomy Olympiads, where the winners are excused from entrance examinations to university if taking astronomy or physics courses.

\section{Astronomy and Computing in Spanish (Aragon) High Schools}

Antonio Elipe ${ }^{1}$, Joaquin Ezpeleta ${ }^{2}$, and Victor Lanchares ${ }^{1}$

1 Dpto. Astronomía, Universidad de Zaragoza, E-50009 Zaragoza, Spain

2 Dpto. de Informatica, Escuela de Magisterio,

E-Pamplona, Navarra, Spain

Astronomy is an optional subject available at some schools, but is generally underfunded. A recent government campaign aims to increase the knowledge of computing and astronomy has been fruitfully linked with this. Details of three specific areas were given: computer-based training; modelling and simulation; and guided programming, where the pupil has to master both astronomical and computational problems.

[In addition to the paper by Dr Acker (given above), four contributions dealt with planetariums and their programmes. These formed a sharp, and interesting contrast, because their size and facilities differed so widely. Further information about European planetarium facilities may be found in "European Planetarium News", published by the Planetarium at Strasbourg. Two Colloquia on European Planetariums have been held in Strasbourg, the first in 1984 and the second in 1988. - Eds.]

\section{The Planetarium at the Palais de la Découverte}

\section{Gérard Oudenot}

Départment d'Astronomie, Palais de la Découverte, av. F.D. Roosevelt, F-75008 Paris, France

This large planetarium has about 250000 visitors every year. It seats 201 persons and has a modern Carl-Zeiss Jena projector. Two or five showings from a series 
of about ten different programmes are given daily to the general public. Special programmes at a much higher level are presented in conjunction with navigation, astronomy and other academic courses.

\section{The Starlab Mobile Planetarium in the Mid-Pyrenees}

Jean-Pierre Chrétien, Jean-Pierre Brunet

1 allée des Roses, F-31520 Ramonville Saint-Agne, France

This planetarium with inflatable dome is available to schools, colleges and youth centres in the region. Each institution using the equipment provides its own lecturer, supported by various levels of documentation, discussion sessions and alternative displays. In the first year about 50 organisations used it, each for about a week, with some 15000 child, and 6000 adult visitors. No serious problems were encountered despite this intensive use.

\section{The Planetarium at a School in Nice}

\section{Jeanine Chappelet}

Planetarium du collège Valéri, B.P. 86, F-06013 Nice Cedex, France

An observatory, laboratory and planetarium were set up by pupils at a school in Nice with assistance from the Club des Pléiades. Various presentations were given, for children and adults, and some with the assistance of astronomers from the $\mathrm{Ob}$ servatory at Nice for teacher-training.

[Full text not received - Eds.]

\section{The Planetarium as a Medium for Teaching Astronomy}

\section{Kunda Barve}

Planetarium, Nehru Centre, Dr Annie Besant Road, Worli, Bombay 400018 , India

Being sited in a large city (with about 10 million inhabitants), the planetarium at Bombay has to try to meet the requirements of a very wide range of visitors, some 3.3 million of whom have seen presentations. These visitors come from very different linguistic, cultural, religious, economic and educational backgrounds, which pose many problems in arranging suitable programmes. (There are 16 major languages and many less common ones.) School children make up the bulk of visitors and presentations for them are linked to their academic grade. Amateur astronomical organisations are gradually coming into existence in India, and the planetarium provides help and encouragement to them. Special shows are made for many individual groups of people, ranging from lovers of poetry and fine arts to invalids and the handicapped. A wide range of additional activities such as competitions, field trips and exhibitions is also provided. 